\title{
A Mechanistic Study on the Amiodarone-Induced Pulmonary Toxicity
}

\author{
Bader Al-Shammari, ${ }^{1}$ Mohamed Khalifa, ${ }^{2}$ Saleh A. Bakheet, ${ }^{2}$ and Moustafa Yasser ${ }^{2}$ \\ ${ }^{1}$ Saudi Food and Drug Authority, AlKhaleej District, Prince Bander Street, P.O. Box 376067, Riyadh 11335, Saudi Arabia \\ ${ }^{2}$ Department of Pharmacology, College of Pharmacy, King Saud University, P.O. Box 2457, Riyadh 11451, Saudi Arabia
}

Correspondence should be addressed to Bader Al-Shammari; badersh@hotmail.com

Received 29 October 2015; Accepted 9 December 2015

Academic Editor: Aramati B. M. Reddy

Copyright (C) 2016 Bader Al-Shammari et al. This is an open access article distributed under the Creative Commons Attribution License, which permits unrestricted use, distribution, and reproduction in any medium, provided the original work is properly cited.

\begin{abstract}
Amiodarone- (AM-) induced pulmonary toxicity (AIPT) is still a matter of research and is poorly understood. In attempting to resolve this issue, we treated Sprague-Dawley rats with AM doses of $80 \mathrm{mg} / \mathrm{kg} / \mathrm{day} / \mathrm{i} . \mathrm{p}$. for one, two, three, and four weeks. The rats were weighed at days $7,14,21$, and 28 and bronchoalveolar lavages (BAL) were obtained to determine total leukocyte count (TLC). For each group, lung weighing, histopathology, and homogenization were performed. Fresh homogenates were used for determination of ATP content, lipid peroxides, GSH, catalase, SOD, GPx, GR activities, NO, and hydroxyproline levels. The results showed a significant decrease in body weight and GSH depletion together with an increase in both lung weight and lung/body weight coefficient in the first week. Considerable increases in lung hydroxyproline level with some histopathological alterations were apparent. Treatment for two weeks produced a significant increase in BAL fluid, TLC, GR activity, and NO level in lung homogenate. The loss of cellular ATP and inhibition of most antioxidative protective enzymatic system appeared along with alteration in SOD activity following daily treatment for three weeks, while, in rats treated with AM for four weeks, more severe toxicity was apparent. Histopathological diagnosis was mostly granulomatous inflammation and interstitial pneumonitis in rats treated for three and four weeks, respectively. As shown, it is obvious that slow oedema formation is the only initiating factor of AIPT; all other mechanisms may occur as a consequence.
\end{abstract}

\section{Introduction}

Amiodarone (AM) is benzofuran derivative with highly effective class III antidysrhythmic activity. It is used for treating ventricular and supraventricular dysrhythmia and may have a role in postmyocardial infraction mortality reduction [1]. However, it is associated with many side effects involving many different organ systems [2]. The most serious side effect of amiodarone is pulmonary toxicity. Amiodaroneinduced pulmonary toxicity (AIPT) is characterized in part by oedema, phospholipidosis, inflammation and thickening of the alveolar septa, intra-alveolar inflammation, and pulmonary fibrosis [3-5]. The etiology of AIPT is unknown. However, several causes have been proposed, including direct or indirect toxicity. It has also been postulated that the cause is complex and multifactorial, possibly involving several mechanisms [6].
Consequently, the mechanism of the adverse reaction is still a matter of research. Thus, the overall objective of this study was to shed light on the possible mechanism(s) associated with AIPT in rats.

\section{Materials and Methods}

2.1. Drug. Amiodarone was obtained from MP Biomedical, USA. Amiodarone solution was freshly prepared by dissolving it in distilled water at $65^{\circ} \mathrm{C}$ and allowing it to cool to room temperature before use in the experiments [7-9].

2.2. Chemicals. Chemicals were obtained from the suppliers as follows. Calcium-free and magnesium-free phosphatebuffered saline (PBS) was obtained from MP Biomedicals, Santa Ana, CA, USA. Thiobarbituric acid (TBA) was obtained 
from Fluka, Buchs, Switzerland. Ellman's reagent $\left(5.5^{\prime}\right.$ dithiobis-(2-nitrobenzoic acid)) (DTNB), sulfanilamide, adenosine triphosphate (ATP), sodium nitrate, and the chemical for measurement of glutathione reductase (GR) activity were obtained from Sigma-Aldrich, St. Louis, MO, USA. Chloramine-T and sodium dodecyl sulfate (SDS) were obtained from Winlab Laboratory Chemicals, Leicestershire, UK. N(Naphthyl)-ethylenediamine dihydrochloride (NEDD) was obtained from Riedel-de Haën, D3010 Seelze, Germany. 4-Dimethylaminobenzaldehyde was obtained from $\mathrm{BDH}$ Chemicals Ltd., Poole, UK. Diagnostic kits for measurement of superoxide dismutase (SOD) and glutathione peroxidase (GPx) were obtained from Randox Laboratories Ltd., Crumlin, UK. All other chemicals were of highest analytical grade.

2.3. Animals and Treatments. Adult Sprague-Dawley rats (Experimental Animal Care Centre, College of Pharmacy, KSU, SA), weighing 130-150 g, were maintained on a $12 \mathrm{~h}$ light/12 h dark cycle and fed a standard animal pellet diet with free access to water.

Rats were randomly allocated into eight groups (10 animals/group). Amiodarone (or equivalent volume of vehicle for control groups) was given $80 \mathrm{mg} / \mathrm{kg} /$ day/i.p. for 1, 2, 3, and 4 weeks for treated groups. Rats underwent the experiment protocols at days 7, 14,21, and 28 following amiodarone injections of their respective group. The dose of amiodarone used in the present study was selected based on the previous report of Kannan et al. [10].

\subsection{Total Leukocyte Count in Bronchoalveolar Lavage Fluid} $B A L F$. Rats were anesthetized using a mixture of ketamine (90 mg/kg/i.p.) and xylazine (10 mg/kg/i.p.). An incision was made in the trachea and $5 \mathrm{~mL}$ of $\mathrm{PBS}$ at $37^{\circ} \mathrm{C}$ was slowly injected into the trachea by catheter needle. This was repeated two more times so that approximately $15 \mathrm{~mL}$ was recovered and kept on ice. Lavage samples were used immediately to measure total leukocyte counts [11].

Total leukocyte counts were measured according to the method of Barbara and Stanley [12]. In brief, cell viability of lung cell was measured using the trypan blue dye exclusion technique. Equal volumes of lung cell suspension and trypan blue stain $(0.047 \%)$ were mixed and a drop on the hemocytometer. The viable cells (unstained) were counted with a low power light microscope.

2.5. Isolation and Homogenization of Lung Samples. After withdrawal of BALF, the lungs were excised and immersed into saline, blotted, weighed, placed directly in liquid nitrogen, and stored at $-80^{\circ} \mathrm{C}$ for further analysis. Homogenization was done freshly. The homogenate was used for determination of biochemical parameters and the freshly removed lungs fragments were fixed in $10 \%$ formalin for histopathology.

2.6. Calculation of Lung/Body Weight Coefficient. Total body weight, lung wet weight, and relative lung/body coefficient were calculated. The lung/body coefficient was calculated as previously reported by Chen et al. [13].
2.7. Determination of Lipid Peroxides (MDA) and Reduced Glutathione (GSH) Content in Lung Homogenates. The lipid peroxide level in lung homogenate was determined as thiobarbituric acid-reactive substances spectrophotometrically at an absorbance of $532 \mathrm{~nm}$, by the method of Ohkawa et al. [14], and the concentrations were expressed as nmole malondialdehyde (MDA) per gram tissue. Tissue levels of the acid soluble thiols, mainly reduced glutathione GSH, were assayed spectrophotometrically at $412 \mathrm{~nm}$, according to the method of Ellman [15]. The GSH content was expressed as $\mu \mathrm{mol} / \mathrm{g}$ lung.

2.8. Determination of Nitric Oxide $\left(\mathrm{NO}_{x}\right)$ in Lung Homogenates. The tissue level of total nitrate/nitrite $\left(\mathrm{NO}_{x}\right)$ was determined by the acidic Griess reaction. Prior to the Griess reaction all nitrate was converted to nitrite using vanadium trichloride as described by Miranda et al. [16].

2.9. Determination of Antioxidant Enzymes in Lung Homogenates. Glutathione reductase was measured by monitoring the oxidation of NADPH at $340 \mathrm{~nm}$ in presence of oxidized glutathione. The glutathione reductase activity is expressed as $\mathrm{nmol} / \mathrm{min} / \mathrm{g}$ lung according to the glutathione reductase assay kit (Sigma-Aldrich, St. Louis, MO, USA) instructions.

Glutathione peroxidase was measured by monitoring the oxidation of NADPH at $340 \mathrm{~nm}$ according to the method of Paglia and Valentine [17]. The glutathione peroxidase activity is expressed as $\mathrm{nmol} / \mathrm{min} / \mathrm{g}$ lung.

Catalase (CAT) activity was determined spectrophotometrically according to the method of Higgins et al. [18], namely, via the assay of hydrogen peroxide $\left(\mathrm{H}_{2} \mathrm{O}_{2}\right)$. Catalase activity is expressed as $\mu \mathrm{mol} / \mathrm{min} / \mathrm{g}$ lung using a molar absorbance of 43.6 for $\mathrm{H}_{2} \mathrm{O}_{2}$.

The superoxide dismutase assay was a slight modification of the indirect inhibition assay developed by McCord and Fridovich [19]. Superoxide dismutase was measured by monitoring the decrease of the rate of detector 2(4-iodophenyl)3-(4-nitrophenol)-5-phenyltetrazolium chloride (INT) reaction with superoxide anion. The superoxide dismutase activity was measured at $505 \mathrm{~nm}$ and is expressed as U/g tissue.

2.10. Determination of Adenosine Triphosphate in Lung Homogenates. Adenosine triphosphate (ATP) levels were determined in lung homogenates using HPLC according to the method reported by Botker et al. [20]. In brief, kidney tissues were homogenized in ice-cold $6 \%$ perchloric acid and centrifuged at $110 \mathrm{~g}$ for $15 \mathrm{~min}$ at $0.5^{\circ} \mathrm{C}$ and the supernatant was injected onto the HPLC after neutralization to $\mathrm{pH}$ 6-7. Chromatographic separation was performed at a flow rate of $1.2 \mathrm{~mL} / \mathrm{min}$, using ODS-Hypersil, $150 \times 4.6 \mathrm{~mm} \mathrm{I.D.} 5 \mathrm{~mm}$ column (Supelco S.A., Gland, Switzerland) and $75 \mathrm{mmol} / \mathrm{L}$ ammonium dihydrogen phosphate as the mobile phase. The peak elution was followed at $254 \mathrm{~nm}$.

2.11. Determination of Hydroxyproline in Lung Homogenates. Hydroxyproline was determined as a biochemical index of fibrosis. In brief, $10 \mu \mathrm{L}$ of lung homogenates was hydrolyzed in $40 \mu \mathrm{L}$ of $2 \mathrm{~N} \mathrm{NaOH}$ at $120^{\circ} \mathrm{C}$ for $20 \mathrm{~min}$. Absorbance of 
each sample was read at $550 \mathrm{~nm}$ and the concentration of hydroxyproline was determined from the standard curve as $\mu \mathrm{g} / \mathrm{g}$ lung according to Reddy and Enwemeka [21].

2.12. Histopathological Examination. Lung specimens were fixed in formalin (10\%) for $24 \mathrm{hrs,} \mathrm{until} \mathrm{the} \mathrm{tissue} \mathrm{became}$ hard enough to be sectioned. Tissues were then embedded in paraffin wax, serially sectioned ( $5 \mu \mathrm{m}$ in thickness), and stained with hematoxylin for $10 \mathrm{~min}$ then counterstained in eosin for $1 \mathrm{~min}$, followed by rapid rinsing in distilled water. Finally, tissues were dehydrated, mounted, and examined using a light microscope (United Medical Laboratories, Riyadh, Saudi Arabia).

2.13. Statistical Analysis. Data are expressed as mean \pm standard error (SE). Statistical comparison between treatment and control groups in each week was done using Student's $t$-test. One-way analysis of variance (ANOVA) followed by Tukey-Kramer multiple comparisons test and Wilcoxon's signed rank test for statistical comparison between more than two groups measures using a software computer program (Graphpad InStat, Version 3). Significance was accepted at $P<0.05$.

\section{Results}

The results of the study revealed that daily intraperitoneal administration of AM ( $80 \mathrm{mg} / \mathrm{kg} /$ day i.p.) for one, two, three, and four weeks resulted in a significant decrease in body weight (Figure 1), indicating that the animals had reacted adversely to the amiodarone treatment. The significant increase in wet lung weight (Figure 2) and lung/body coefficient (Figure 3) and the large increase in total cell count number in BALF (Figure 4) indicated that oedema started early and was followed by inflammation.

$\mathrm{AM}$ given to rats in a dose of $80 \mathrm{mg} / \mathrm{kg} /$ day i.p. decreased the lung content of malondialdehyde (MDA) (Figure 5) compared to the value obtained from the control group $(68.10 \pm 6.27$ to $47.58 \pm 6.10,107.43 \pm 7.10$ to $45.61 \pm 3.52$, and $107.4 \pm 7.1$ to $30.56 \pm 2.64 \mathrm{nmol} / \mathrm{g}$ lung for two, three, and four weeks, resp.), which can be explained as indicated as part of the antioxidant effect of AM. Throughout all the treatment periods, AM decreased the GSH level significantly in lung homogenate (Figure 6). The level was decreased by $50 \%$ after one week, $34.8 \%$ after two weeks, $52.6 \%$ after three weeks, and $\sim 100 \%$ after four weeks as compared with the untreated group following intraperitoneal administration of AM.

In the current study, daily administration of amiodarone for two, three, and four weeks resulted in a significant increase in nitrate/nitrite concentration in the lung homogenate compared to a control value (Figure 7). However, administration of AM for two weeks resulted in a significant decrease in the level of catalase (Figure 8) and glutathione peroxidase (Figure 9) together with a significant increase in glutathione reductase activity (Figure 10). The same results were obtained following daily administration of amiodarone for three weeks; the only difference was the observed decrease in the SOD level (Figure 11). Daily administration of amiodarone for

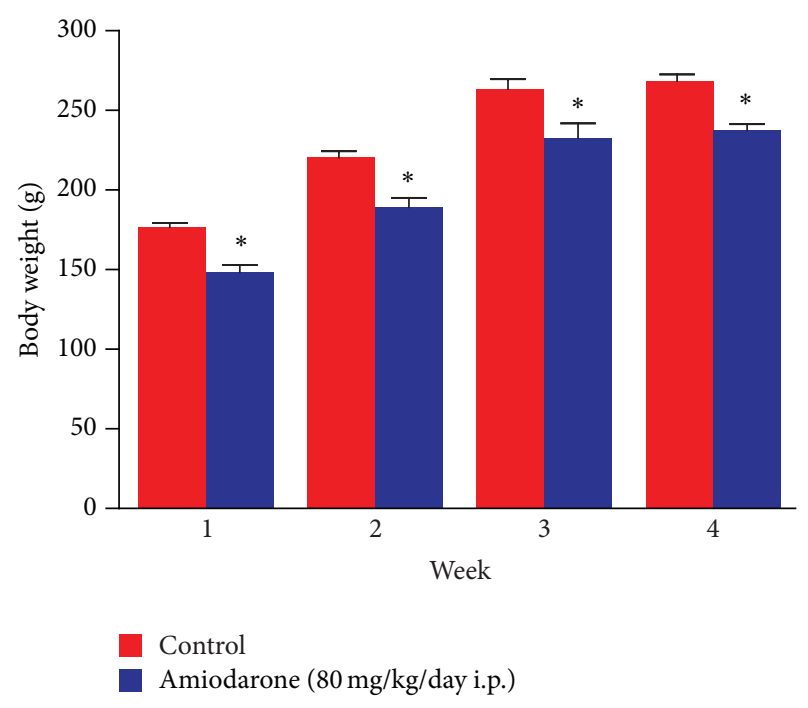

FIGURE 1: The effect of amiodarone on rat body weight. Amiodarone was given $(80 \mathrm{mg} / \mathrm{kg} /$ day i.p.) for one, two, three, and four weeks. Each group was compared with its respective control. The body weight was determined on days 7, 14, 21, and 28. The data represent the mean \pm SEM of 10 rats. *Significant difference from control group $(P<0.05)$.

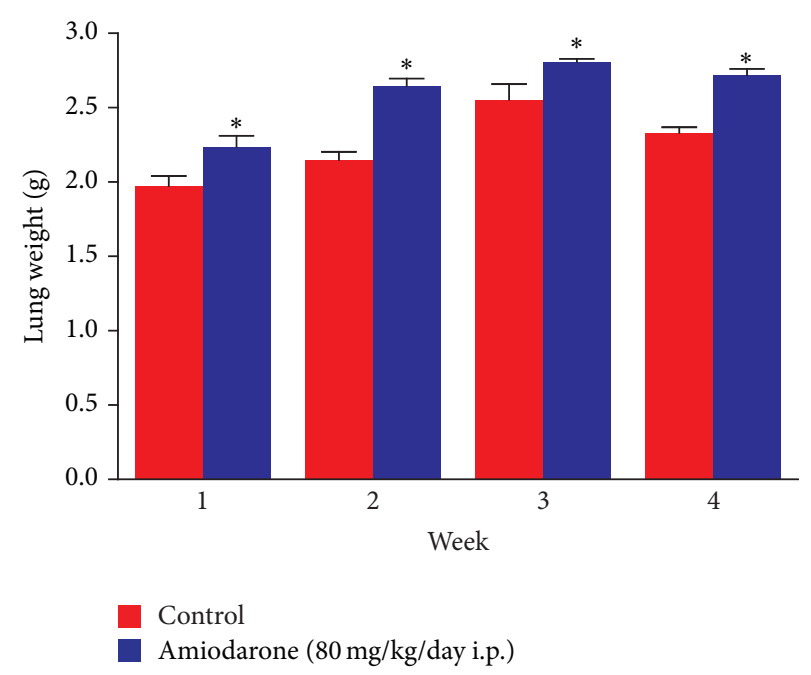

FIGURE 2: The effect of amiodarone on rat lung weight. Amiodarone was given $(80 \mathrm{mg} / \mathrm{kg} /$ day i.p.) for one, two, three, and four weeks. Each group was compared with its respective control. The lung weight was determined on days 7, 14, 21, and 28. The data represent the mean \pm SEM of 10 rats. *Significant difference from control group $(P<0.05)$.

four weeks produced a significant decrease in the activity of all antioxidant enzymes.

The results obtained in the current study clearly demonstrate that daily administration of amiodarone for two and three weeks produced a significant depletion in ATP level (Figure 12) from $71.88 \pm 4.25$ to $36.45 \pm 2.69 \mathrm{nmol} / \mathrm{g}$ lung and from $50.37 \pm 0.73$ to $32.05 \pm 2.01 \mathrm{nmol} / \mathrm{g}$ lung, respectively.

The lung hydroxyproline of amiodarone-treated groups was significantly increased (Figure 13) by approximately 


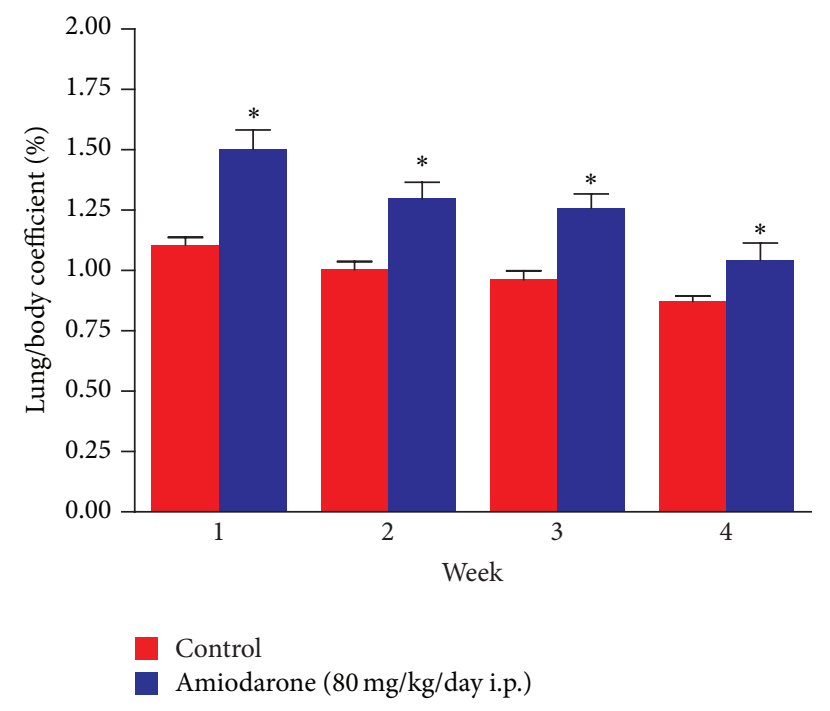

FIgURE 3: The effect of amiodarone on rat lung/body coefficient. Amiodarone was given $(80 \mathrm{mg} / \mathrm{kg} /$ day i.p.) for one, two, three, and four weeks. Each group was compared with its respective control. The lung/body coefficient was calculated on days 7, 14, 21, and 28. The data represent the mean \pm SEM of 10 rats. *Significant difference from control group $(P<0.05)$.

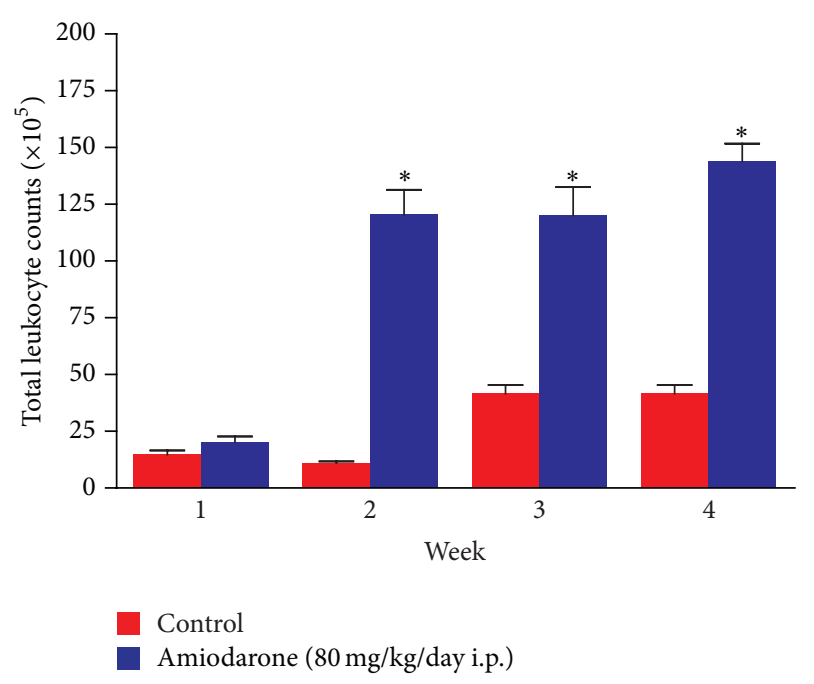

FIGURE 4: The effect of amiodarone on total leukocyte count in bronchoalveolar lavage fluid of rat. Amiodarone was given ( $80 \mathrm{mg} / \mathrm{kg} /$ day i.p.) for one, two, three, and four weeks. Each group was compared with its respective control. The total leukocyte count was calculated on days $7,14,21$, and 28 . The data represent the mean \pm SEM of 10 rats. *Significant difference from control group $(P<0.01)$.

$50 \%, 61 \%, 71 \%$, and $70.6 \%$ at one, two, three, and four weeks, respectively, as compared to the water control groups. Histopathological diagnosis was mostly interstitial capillary dilation with some lymphocytes, granulomatous inflammation, interstitial pneumonitis, and thickened alveolar walls in the treated groups (Figures 14-18).

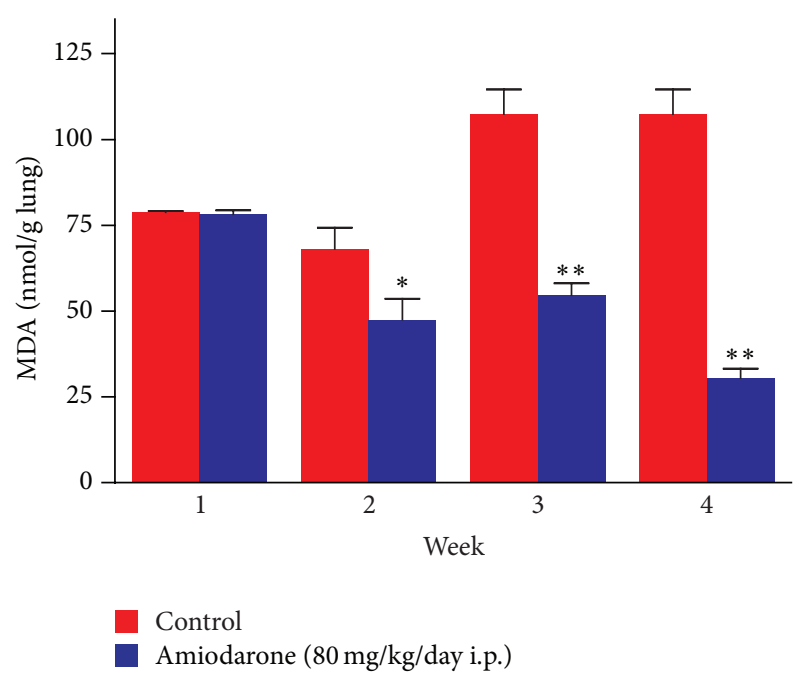

FIGURE 5: The effect of amiodarone on malondialdehyde MDA level in lung rat homogenate. Amiodarone was given ( $80 \mathrm{mg} / \mathrm{kg} /$ day i.p.) for one, two, three, and four weeks. MDA was measured on days 7, 14, 21 , and 28 . The data represent the mean \pm SEM of 10 rats. *Significant difference from control group $(P<0.05)$. ${ }^{* *}$ Significant difference from control group $(P<0.01)$.

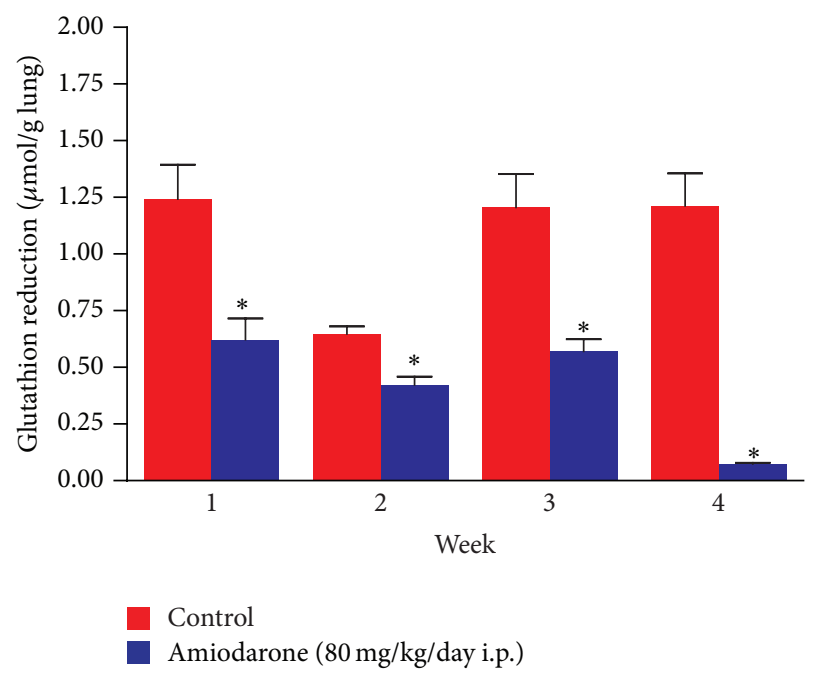

FIGURE 6: The effect of amiodarone on reduced glutathione (GSH) level in rat lung homogenate. Amiodarone was given $(80 \mathrm{mg} / \mathrm{kg} /$ day i.p.) for one, two, three, and four weeks. Each group was compared with its respective control. The reduced glutathione was measured on days $7,14,21$, and 28 . The data represent the mean \pm SEM of 10 rats. ${ }^{*}$ Significant difference from control group $(P<0.01)$.

\section{Discussion}

It is evident that the most important characteristic features obtained following daily i.p. administration of amiodarone in rats for one week include decreased body weight together with an increase in both lung weight and lung/body weight coefficient. Glutathione depletion was observed. Considerable increases in lung hydroxyproline level with some histopathological alterations are apparent. 


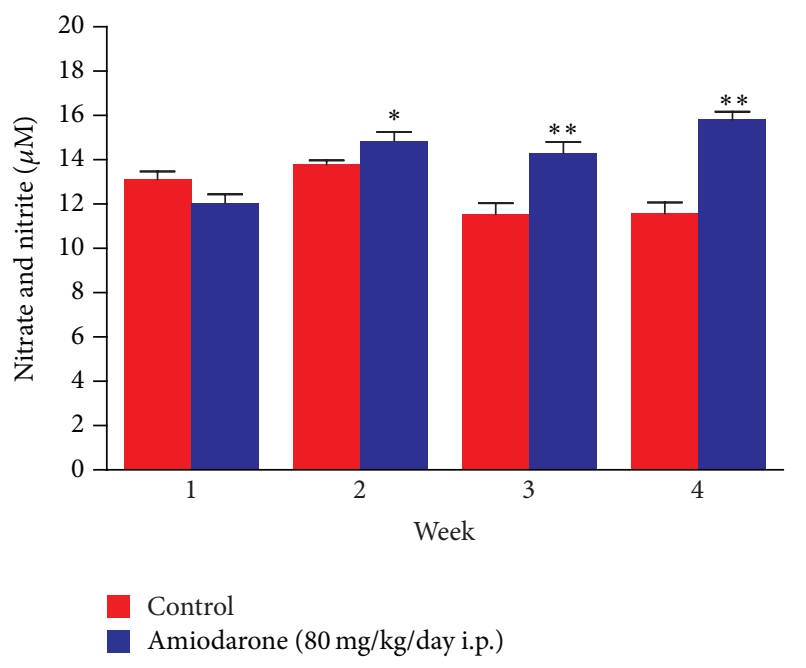

FIGURE 7: The effect of amiodarone on nitric oxide as nitrate/nitrite concentration in rat lung homogenate. Amiodarone was given ( $80 \mathrm{mg} / \mathrm{kg} /$ day i.p.) for one, two, three, and four weeks. Each group was compared with its respective control. The nitrate and nitrite concentration was measured on days $7,14,21$, and 28 . The data represent the mean \pm SEM of 10 rats. *Significant difference from control group $(P<0.05) .{ }^{* *}$ Significant difference from control group $(P<0.01)$.

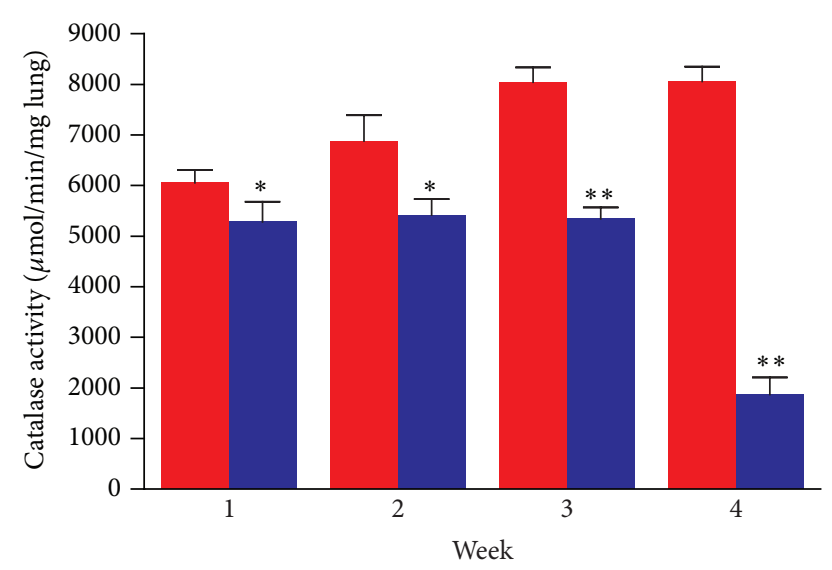

Control

Amiodarone ( $80 \mathrm{mg} / \mathrm{kg} /$ day i.p.)

FIGURE 8: The effect of amiodarone on catalase activity in rat lung homogenate. Amiodarone was given $(80 \mathrm{mg} / \mathrm{kg} /$ day i.p.) for one, two, three, and four weeks. Each group was compared with its respective control. The catalase activity was measured on days 7,14 , 21 , and 28 . The data represent the mean \pm SEM of 10 rats. *Significant difference from control group $(P<0.05)$. ${ }^{* *}$ Significant difference from control group $(P<0.01)$.

The observed change in lung glutathione status is, therefore, indicative of specific pulmonary response to amiodarone exposure, which is in good agreement with data obtained from several investigations.

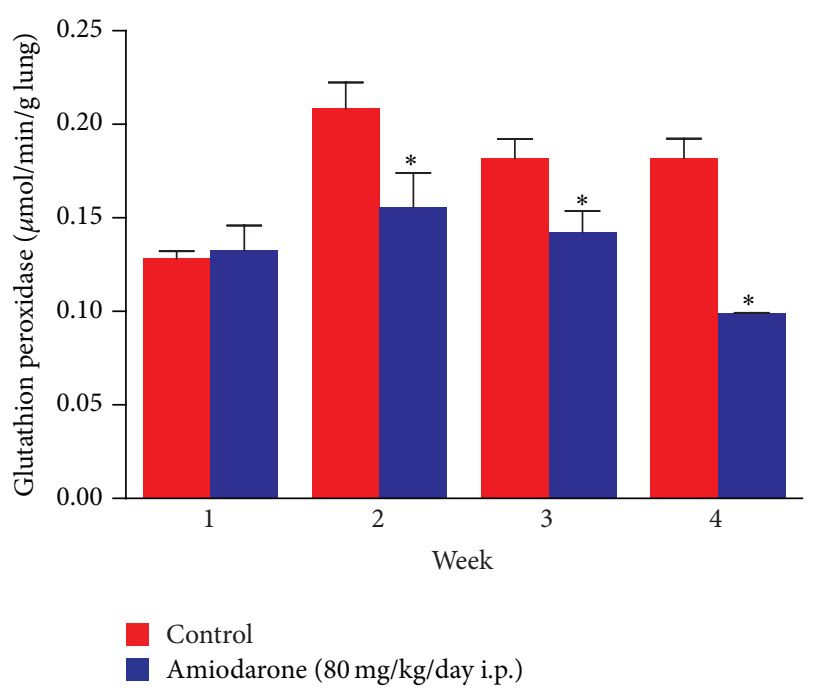

FIGURE 9: The effect of amiodarone on glutathione peroxidase activity in rat lung homogenate. Amiodarone was given $(80 \mathrm{mg} / \mathrm{kg} / \mathrm{day}$ i.p.) for one, two, three, and four weeks. Each group was compared with its respective control. The glutathione peroxidase activity was measured on days $7,14,21$, and 28 . The data represent the mean \pm SEM of 10 rats. * Significant difference from control group $(P<0.05)$.

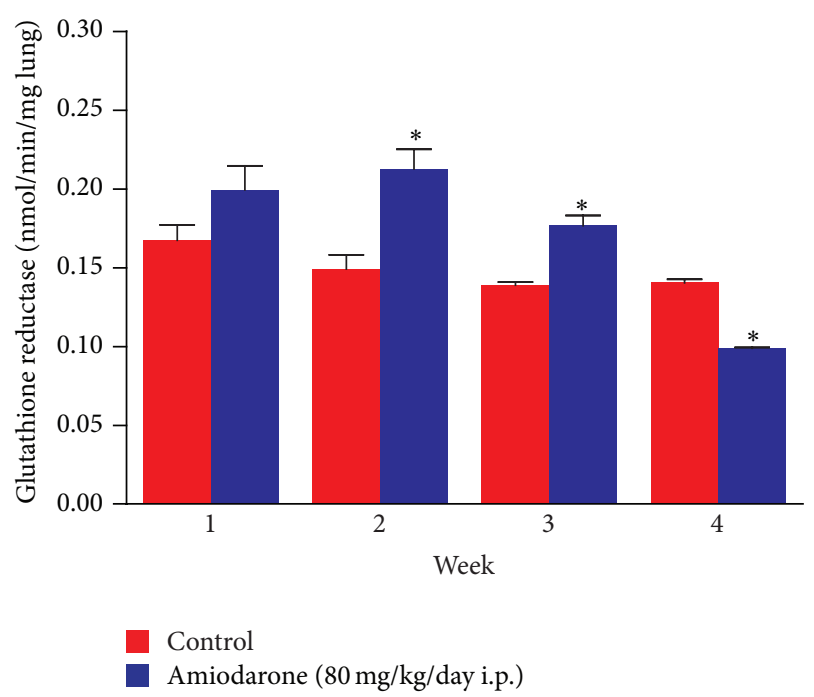

FIGURE 10: The effect of amiodarone on glutathione reductase activity in rat lung homogenate. Amiodarone was given $(80 \mathrm{mg} / \mathrm{kg} /$ day i.p.) for one, two, three, and four weeks. Each group was compared with its respective group. The glutathione reductase activity was measured on days $7,14,21$, and 28 . The data represent the mean \pm SEM of 10 rats. * Significant difference from control group $(P<0.05)$.

Further studies have revealed that amiodarone is metabolized to an aryl radical that may give rise to other reactive oxygen species $[22,23]$.

Both catalytic and scavenger antioxidants have been shown to attenuate amiodarone-induced lung injury and fibrosis in animals [24].

Reactive oxygen species (ROS, e.g., $\mathrm{H}_{2} \mathrm{O}_{2}$ ) cause endothelial injury leading to oedema, thrombosis, and inflammation, 


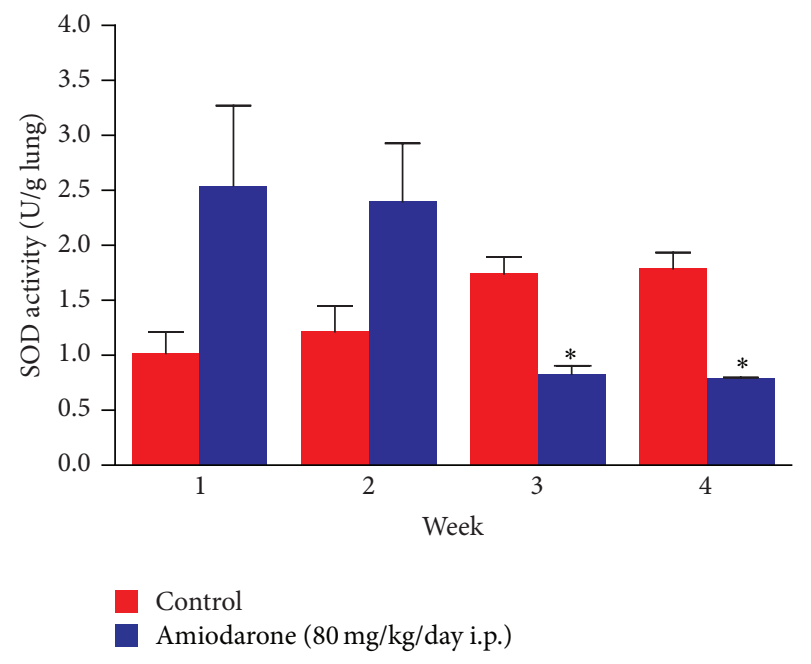

FIGURE 11: The effect of amiodarone on superoxide dismutase activity in rat lung homogenate. Amiodarone was given $(80 \mathrm{mg} / \mathrm{kg} / \mathrm{day}$ i.p.) for one, two, three, and four weeks. Each group was compared with its respective control. The superoxide dismutase activity was measured on days $7,14,21$, and 28 . The data represents the mean \pm SEM of 10 rats. "Significant difference from control group $(P<0.01)$.

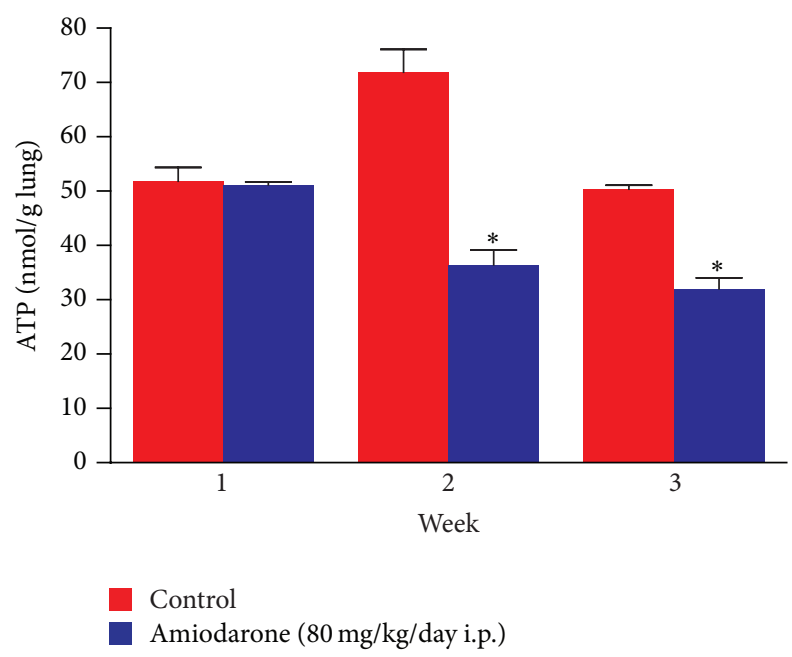

FIGURE 12: The effect of amiodarone on ATP level in rat lung homogenate. Amiodarone was given $(80 \mathrm{mg} / \mathrm{kg} /$ day i.p.) for one, two, and three weeks. The ATP level was measured on days 7, 14, and 21 . The data represent the mean \pm SEM of 10 rats. *Significant difference from control group $(P<0.01)$.

contributing to morbidity and mortality in acute lung injury (ALI), ischemia-reperfusion (I/R), and many other disease conditions [25-30].

ROS cause endothelial dysfunction manifested by increased permeability, leukocyte recruitment, adhesion and transmigration, thrombosis, and other pathways initiating and propagating inflammation [31, 32]. However, current means for vascular protection have provided inconsistent results in many animal and clinical studies, at least in part due to suboptimal delivery of antioxidants to the endothelial cells.

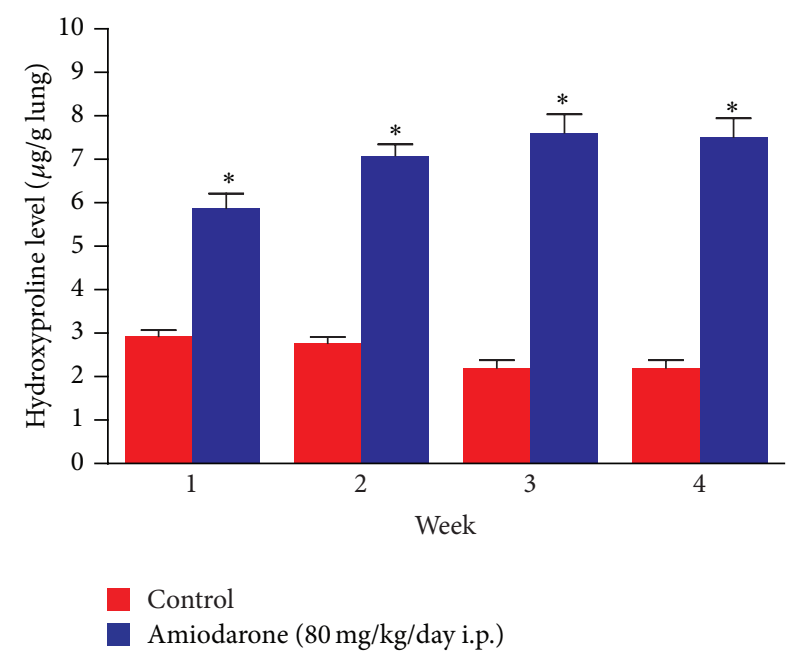

FIGURE 13: The effect of amiodarone on hydroxyproline content of rat lung homogenate. Amiodarone was given ( $80 \mathrm{mg} / \mathrm{kg} /$ day i.p.) for one, two, three, and four weeks. Each group was compared with its respective control. The hydroxyproline content was measured on days $7,14,21$, and 28 . The data represents the mean \pm SEM of 10 rats. *Significant difference from control group $(P<0.01)$.

On the other hand, the pulmonary endothelium represents the source of ROS generated via diverse enzymatic mechanisms by leukocytes, alveolar macrophages, and endothelial cells themselves [31, 33-35].

Indicators of general lung cell injury, including lung weights and lung/body weight coefficient, all increased early after amiodarone dosing and remained elevated at every time period examined. Interstitial capillary dilatation with some lymphocytes produced by amiodarone in the present study may explain the effect of the drug in increasing capillary permeability and subsequent oedema formation. The increased hydroxyproline level may correlate with oedema that occurs early after amiodarone administration and infiltration by inflammatory cells days after.

The data obtained in the present study suggest that inflammation is absent in early AIPT and may occur as a consequence of lung oedema or the process that leads to oedema formation (Figures 1-4).

In rats treated with amiodarone for two weeks, an increased total leukocyte count is observed in BALF. Such increase is an informative measure of inflammation in the lung.

The elevation of glutathione reductase activity observed most likely represents inflammation of lung and the associated influx of glutathione reductase-containing inflammatory cells rather than an adaptive induction due to oxidative stress. Loss of cellular ATP can be considered as a pivotal event in the initiation of amiodarone cytotoxicity in the lung. The inhibition of most of the antioxidative protective enzymatic system supports the generation of more ROS and subsequent role of oxidative stress in AIPT.

The alteration in SOD activity produced by administration of amiodarone for three weeks is indicative of changes in the handling of ROS. 

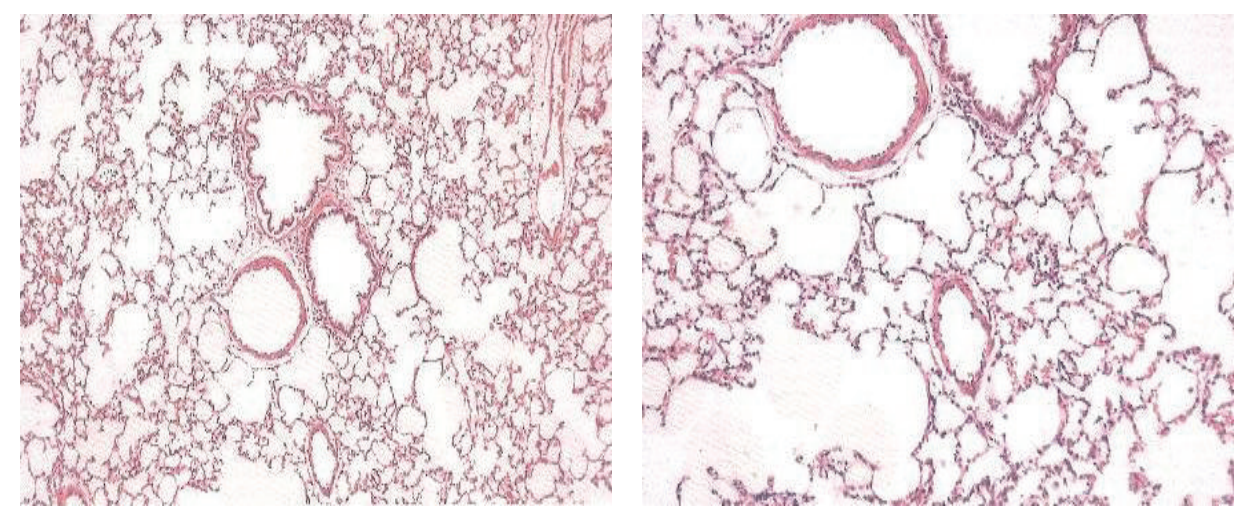

FIGURE 14: Histopathology of control rat. Microscopic description: normal rat lung.
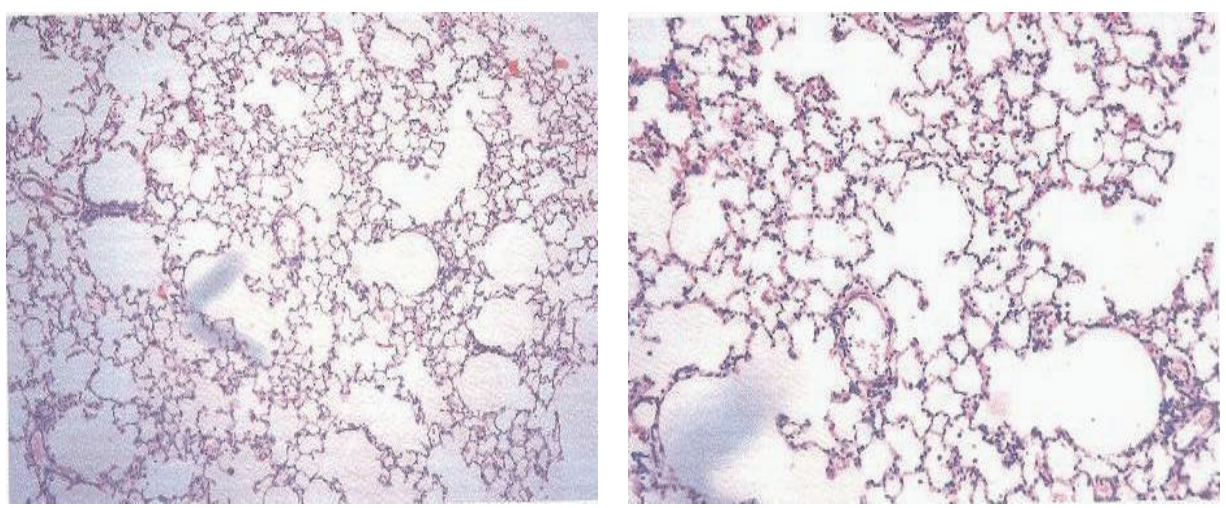

FIGURE 15: Effect of amiodarone on rat lung histopathology. Amiodarone was given ( $80 \mathrm{mg} / \mathrm{kg} / \mathrm{day}$ i.p.) for one week. Microscopic description: examination reveals fragments of lung tissue showing vascular congestion, unremarkable bronchi, and interstitial capillary dilation with some lymphocytes.
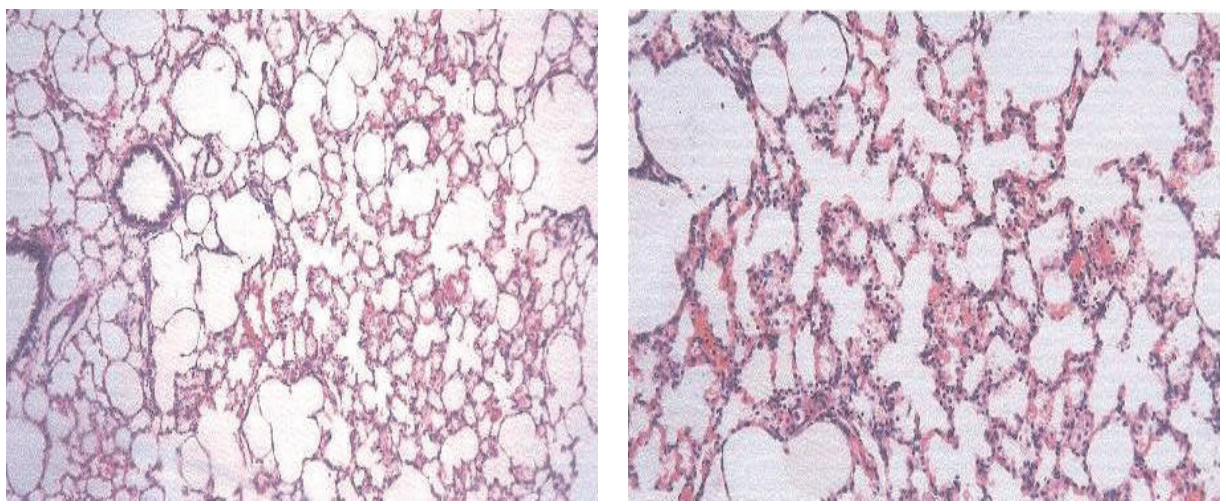

Figure 16: Effect of amiodarone on rat lung histopathology. Amiodarone was given $(80 \mathrm{mg} / \mathrm{kg} /$ day i.p.) for two weeks. Microscopic description: examination reveals fragments of lung tissue showing interstitial vascular congestion and moderate lymphocytic infiltrate. The bronchi are unremarkable.

The increased NO observed is indicative of oxidantrelated tissue injury by formation of highly reactive nitrogen intermediates. For example, NO reacts with superoxide and generates a highly reactive metabolite, peroxynitrite $\left(\mathrm{OONO}^{-}\right)$, which is presumed to be largely responsible for most of the adverse effects of excessive generation of NO [36]. Since this reaction occurs at a nearly diffusion limited rate, it is assumed that NO can outcompete superoxide dismutases (SOD) for reaction with $\mathrm{O}_{2}{ }^{-}$and that $\mathrm{OONO}^{-}$will be generated as a consequence of the simultaneous production of $\mathrm{O}_{2}{ }^{-}$and NO [37]. Thus, the role of NO in AIPT cannot be ruled out. Targeting SOD or SOD mimetics may help to decompose superoxide anion and thus prevent inactivation of nitric oxide and oxidative nitration in the tissues [38, 39]. 

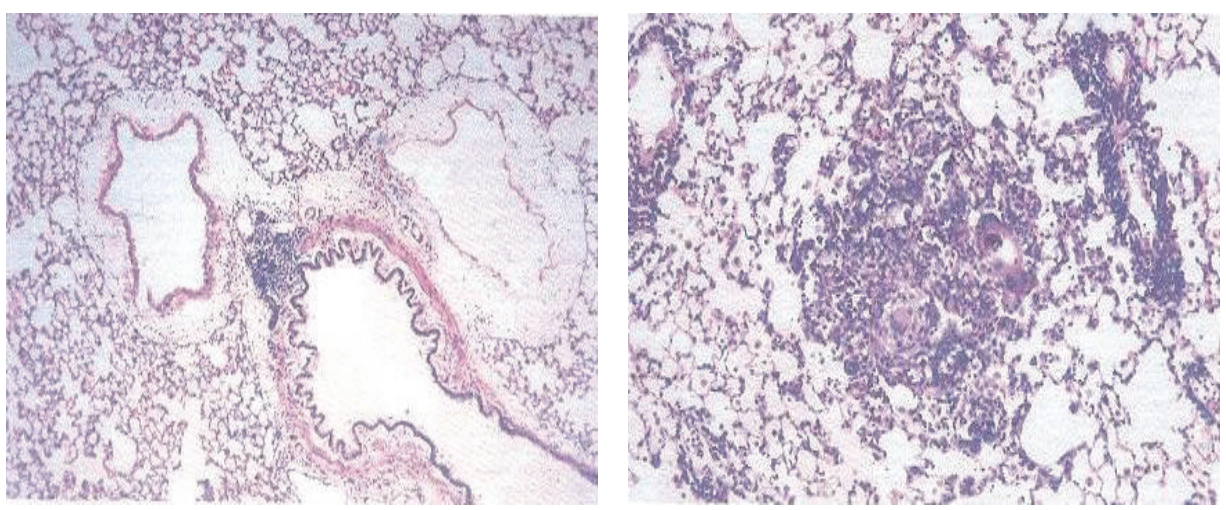

Figure 17: Effect of amiodarone on rat lung histopathology. Amiodarone was given $(80 \mathrm{mg} / \mathrm{kg} / \mathrm{day}$ i.p.) for three weeks. Microscopic description: inflamed lung tissue showing nodular collection of lymphocytes and subpleural granulomas with multinucleated giant cells. The lung tissue is emphysematous and congested. Histopathologic diagnosis: granulomatous inflammation.
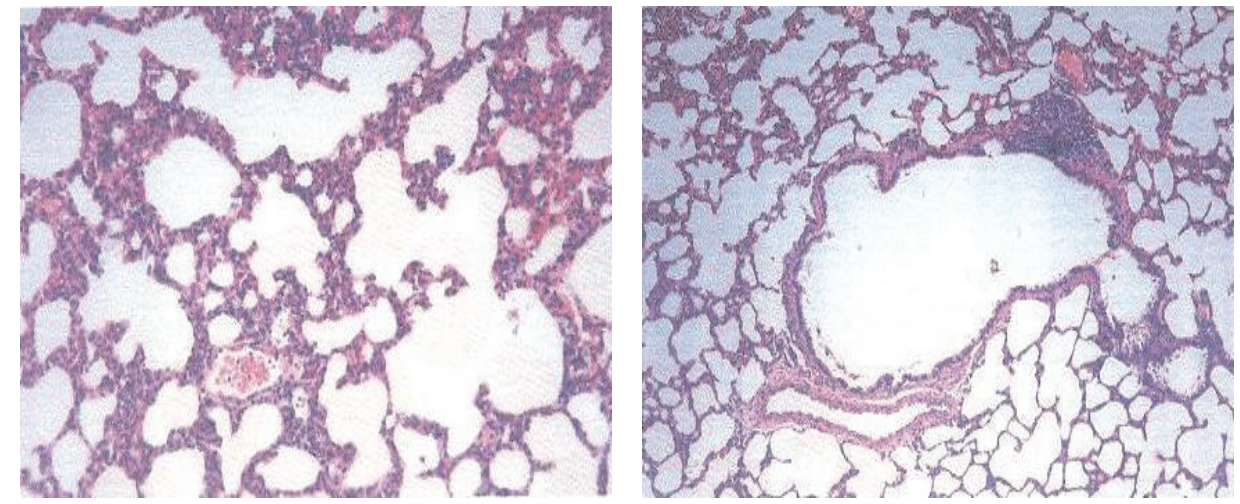

FIGURE 18: Effect of amiodarone on rat lung histopathology. Amiodarone was given $(80 \mathrm{mg} / \mathrm{kg} / \mathrm{day}$ i.p. $)$ for four weeks. Microscopic description: emphysematous lung tissue showing nodular lymphocytic collection and thickened alveolar walls that contain lymphocytes and neutrophils. Histopathologic diagnosis: interstitial pneumonitis.

The study was extended to a fourth week in a trial to follow up the progression of AIPT; more severe toxicity is apparent with approximately the same changes seen in rats treated with amiodarone for three weeks except for a significant reduction in glutathione reductase activity which can be explained as a sort of imbalance between oxidant and antioxidant systems. Daily i.p. administrations of amiodarone for five weeks resulted in a considerable mortality.

In conclusion, it is evident that AIPT occurs in rats following daily i.p. administration in a sequence of oedema formation, inflammatory reactions, and severe imbalance between ROS production and antioxidant defenses (oxidative stress) ending ultimately in severe lung toxicity. Such oedema may lead to pulmonary fibrosis and we think the future research should focus on better understanding of the mechanisms involved in oedema formation by amiodarone.

\section{Disclosure}

This research was partial fulfillment of the requirements for the M.S. degree in toxicology for Bader Mukhlef AlShammari.

\section{Conflict of Interests}

The authors have no conflict of interests that is directly or indirectly relevant to the content of this research.

\section{Acknowledgment}

The authors would like to thank King Saud University, Saudi Arabia, for the funding that supported this research.

\section{References}

[1] D. Chen and T. R. Hedges III, "Amiodarone optic neuropathyreview," Seminars in Ophthalmology, vol. 18, no. 4, pp. 169-173, 2003.

[2] E. A. Raeder, P. J. Podrid, and B. Lown, "Side effects and complications of amiodarone therapy," American Heart Journal, vol. 109, no. 5, pp. 975-983, 1985.

[3] J. W. Mason, "Amiodarone," The New England Journal of Medicine, vol. 316, no. 8, pp. 455-466, 1987.

[4] W. J. Martin II and E. C. Rosenow III, "Amiodarone pulmonary toxicity. Recognition and pathogenesis (Part 2)," Chest, vol. 93, no. 6, pp. 1242-1246, 1988. 
[5] R. G. Leeder, J. F. Brien, and T. E. Massey, "Investigation of the role of oxidative stress in amiodarone-induced pulmonary toxicity in the hamster," Canadian Journal of Physiology and Pharmacology, vol. 72, no. 6, pp. 613-621, 1994.

[6] M. J. Reasor and S. Kacew, "An evaluation of possible mechanisms underlying amiodarone-induced pulmonary toxicity," Proceedings of the Society for Experimental Biology and Medicine, vol. 212, no. 4, pp. 297-304, 1996.

[7] T. L. Blake and M. J. Reasor, "Pulmonary responses to amiodarone in hamsters: comparison of intratracheal and oral administrations," Toxicology and Applied Pharmacology, vol. 131, no. 2, pp. 325-331, 1995.

[8] A. Matsui, H. Matsuo, H. Takanaga, S. Sasaki, M. Maeda, and Y. Sawada, "Prediction of catalepsies induced by amiodarone, aprindine and procaine: similarity in conformation of diethylaminoethyl side chain," Journal of Pharmacology and Experimental Therapeutics, vol. 287, no. 2, pp. 725-732, 1998.

[9] W. H. Chung, B. M. Bennett, W. J. Racz, J. F. Brien, and T. E. Massey, "Induction of c-jun and TGF- $\beta 1$ in Fischer 344 rats during amiodarone-induced pulmonary fibrosis," American Journal of Physiology - Lung Cellular and Molecular Physiology, vol. 281, no. 5, pp. L1180-L1188, 2001.

[10] R. Kannan, J. S. M. Sarma, M. Guha, and K. Venkataraman, "Tissue drug accumulation and ultrastructural changes during amiodarone administration in rats," Toxicological Sciences, vol. 13, no. 4, pp. 793-803, 1989.

[11] R. F. Henderson, "Use of bronchoalveolar lavage to detect respiratory tract toxicity of inhaled material," Experimental and Toxicologic Pathology, vol. 57, supplement 1, pp. 155-159, 2005.

[12] B. M. Barbara and M. S. Stanley, "Preparation of mouse cell suspension," in Selected Methods in Cellular Immunology, B. B. Mishell and S. M. Shiigi, Eds., pp. 3-27, W. H. Freeman and Co, San Francisco, Calif, USA, 1980.

[13] Y. Chen, J. Chen, J. Dong, and Y. Jin, "Comparing study of the effect of nanosized silicon dioxide and microsized silicon dioxide on fibrogenesis in rats," Toxicology and Industrial Health, vol. 20, no. 1-5, pp. 21-27, 2004.

[14] H. Ohkawa, N. Ohishi, and K. Yagi, "Assay for lipid peroxides in animal tissues by thiobarbituric acid reaction," Analytical Biochemistry, vol. 95, no. 2, pp. 351-358, 1979.

[15] G. L. Ellman, "Tissue sulfhydryl groups," Archives of Biochemistry and Biophysics, vol. 82, no. 1, pp. 70-77, 1959.

[16] K. M. Miranda, M. G. Espey, and D. A. Wink, "A rapid, simple spectrophotometric method for simultaneous detection of nitrate and nitrite," Nitric Oxide, vol. 5, no. 1, pp. 62-71, 2001.

[17] D. E. Paglia and W. N. Valentine, "Studies on the quantitative and qualitative characterization of erythrocyte glutathione peroxidase," The Journal of Laboratory and Clinical Medicine, vol. 70, no. 1, pp. 158-169, 1967.

[18] C. P. Higgins, R. L. Baehner, J. McCallister, and L. A. Boxer, "Polymorphonuclear leukocyte species differences in the disposal of hydrogen peroxide $\left(\mathrm{H}_{2} \mathrm{O}_{2}\right)$," Proceedings of the Society for Experimental Biology and Medicine, vol. 158, no. 3, pp. 478481, 1978.

[19] J. M. McCord and I. Fridovich, "Superoxide dismutase. An enzymic function for erythrocuprein (hemocuprein)," The Journal of Biological Chemistry, vol. 244, no. 22, pp. 6049-6055, 1969.

[20] H. E. Botker, H. H. Kimose, P. Helligso, and T. T. Nielsen, "Analytical evaluation of high energy phosphate determination by high performance liquid chromatography in myocardial tissue," Journal of Molecular and Cellular Cardiology, vol. 26, no. 1, pp. 41-48, 1994.
[21] G. K. Reddy and C. S. Enwemeka, "A simplified method for the analysis of hydroxyproline in biological tissues," Clinical Biochemistry, vol. 29, no. 3, pp. 225-229, 1996.

[22] A. Vereckei, A. Blazovics, I. Gyorgy et al., "The role of free radicals in the pathogenesis of amiodarone toxicity," Journal of Cardiovascular Electrophysiology, vol. 4, no. 2, pp. 161-177, 1993.

[23] A. C. Nicolescu, J. L. Comeau, B. C. Hill et al., "Aryl radical involvement in amiodarone-induced pulmonary toxicity: investigation of protection by spin-trapping nitrones," Toxicology and Applied Pharmacology, vol. 220, no. 1, pp. 60-71, 2007.

[24] B. J. Day, "Antioxidants as potential therapeutics for lung fibrosis," Antioxidants and Redox Signaling, vol. 10, no. 2, pp. 355-370, 2008.

[25] R. B. Fox, J. R. Hoidal, D. M. Brown, and J. E. Repine, "Pulmonary inflammation due to oxygen toxicity: involvement of chemotactic factors and polymorphonuclear leukocytes," American Review of Respiratory Disease, vol. 123, no. 5, pp. 521523, 1981.

[26] J. A. Leff, P. E. Parsons, C. E. Day et al., "Serum antioxidants as predictors of adult respiratory distress syndrome in patients with sepsis," The Lancet, vol. 341, no. 8848, pp. 777-780, 1993.

[27] J. F. Pittet, R. C. Mackersie, T. R. Martin, and M. A. Matthay, "Biological markers of acute lung injury: prognostic and pathogenetic significance," American Journal of Respiratory and Critical Care Medicine, vol. 155, no. 4, pp. 1187-1205, 1997.

[28] F. Chabot, J. A. Mitchell, J. M. C. Gutteridge, and T. W. Evans, "Reactive oxygen species in acute lung injury," European Respiratory Journal, vol. 11, no. 3, pp. 745-757, 1998.

[29] P. A. Ward and G. W. Hunninghake, "Lung inflammation and fibrosis," American Journal of Respiratory and Critical Care Medicine, vol. 157, no. 4, pp. S123-S129, 1998.

[30] C. Sittipunt, K. P. Steinberg, J. T. Ruzinski et al., "Nitric oxide and nitrotyrosine in the lungs of patients with acute respiratory distress syndrome," American Journal of Respiratory and Critical Care Medicine, vol. 163, no. 2, pp. 503-510, 2001.

[31] B. A. Freeman and J. D. Crapo, "Biology of disease: free radicals and tissue injury," Laboratory Investigation, vol. 47, no. 5, pp. 412-426, 1982.

[32] A. Siflinger-Birnboim and A. B. Malik, "Neutrophil adhesion to endothelial cells impairs the effects of catalase and glutathione in preventing endothelial injury," Journal of Cellular Physiology, vol. 155, no. 2, pp. 234-239, 1993.

[33] R. G. Eckenhoff, C. Dodia, Z. Tan, and A. B. Fisher, "Oxygendependent reperfusion injury in the isolated rat lung," Journal of Applied Physiology, vol. 72, no. 4, pp. 1454-1460, 1992.

[34] A. B. Al-Mehdi, G. Zhao, C. Dodia et al., "Endothelial NADPH oxidase as the source of oxidants in lungs exposed to ischemia or high K+, Circulation Research, vol. 83, no. 7, pp. 730-737, 1998.

[35] C. Li and R. M. Jackson, "Reactive species mechanisms of cellular hypoxia-reoxygenation injury," American Journal of Physiology-Cell Physiology, vol. 282, no. 2, pp. C227-C241, 2002.

[36] J. S. Beckman and W. H. Koppenol, "Nitric oxide, superoxide, and peroxynitrite: the good, the bad, and the ugly", The American Journal of Physiology, vol. 271, no. 5, pp. C1424-C1437, 1996.

[37] A. van der Vliet, J. P. Eiserich, M. K. Shigenaga, and C. E. Cross, "Reactive nitrogen species and tyrosine nitration in the respiratory tract: epiphenomena or a pathobiologic mechanism of disease?" American Journal of Respiratory and Critical Care Medicine, vol. 160, no. 1, pp. 1-9, 1999. 
[38] I. Fridovich, "Superoxide radical and superoxide dismutases," Annual Review of Biochemistry, vol. 64, pp. 97-112, 1995.

[39] Z. Vujaskovic, I. Batinic-Haberle, Z. N. Rabbani et al., "A small molecular weight catalytic metalloporphyrin antioxidant with superoxide dismutase (SOD) mimetic properties protects lungs from radiation-induced injury," Free Radical Biology and Medicine, vol. 33, no. 6, pp. 857-863, 2002. 


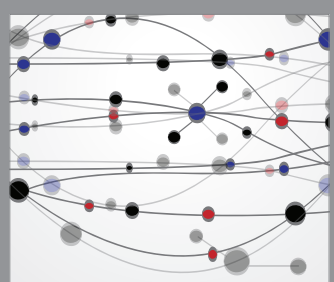

The Scientific World Journal
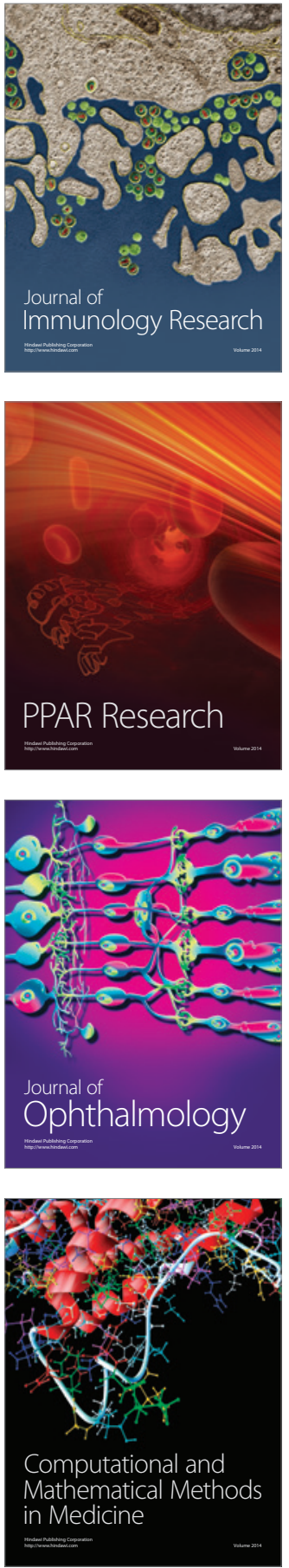

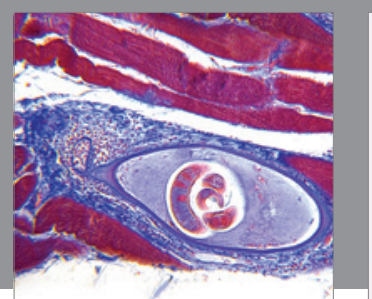

Gastroenterology Research and Practice

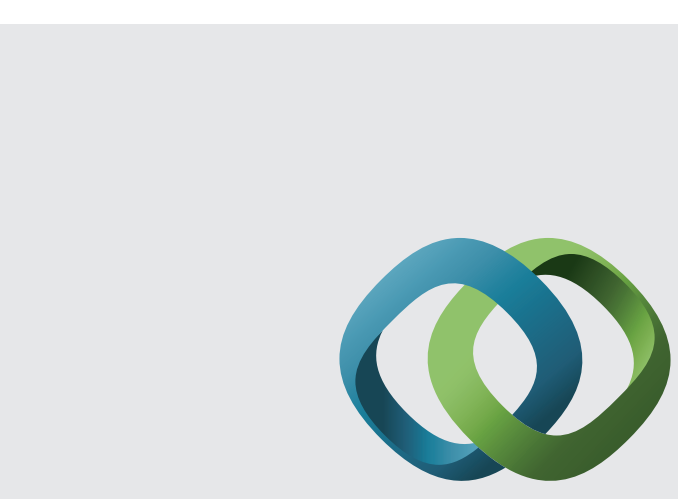

\section{Hindawi}

Submit your manuscripts at

http://www.hindawi.com
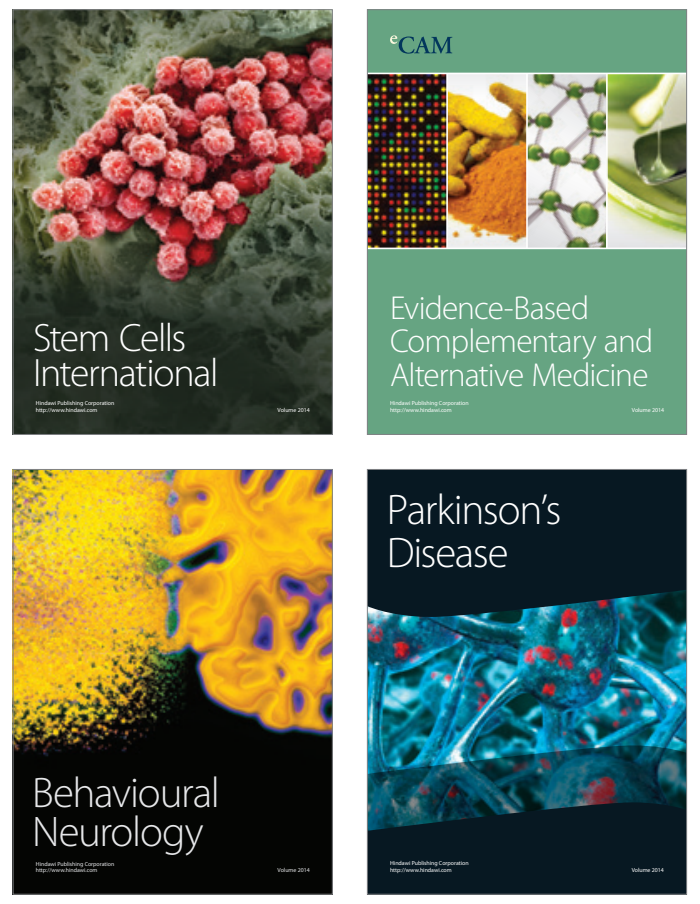
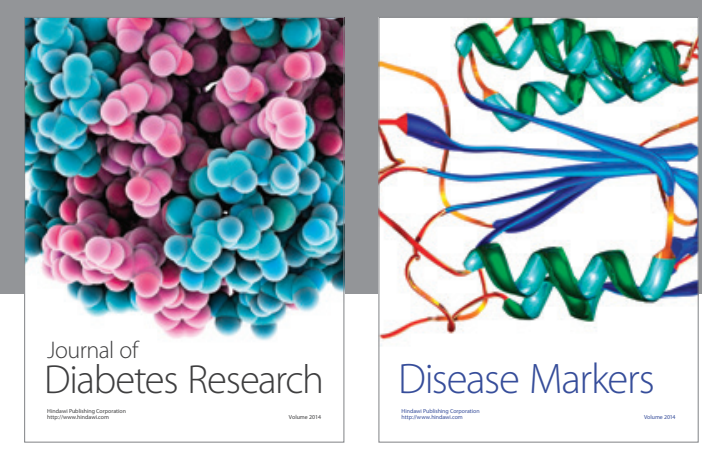

Disease Markers
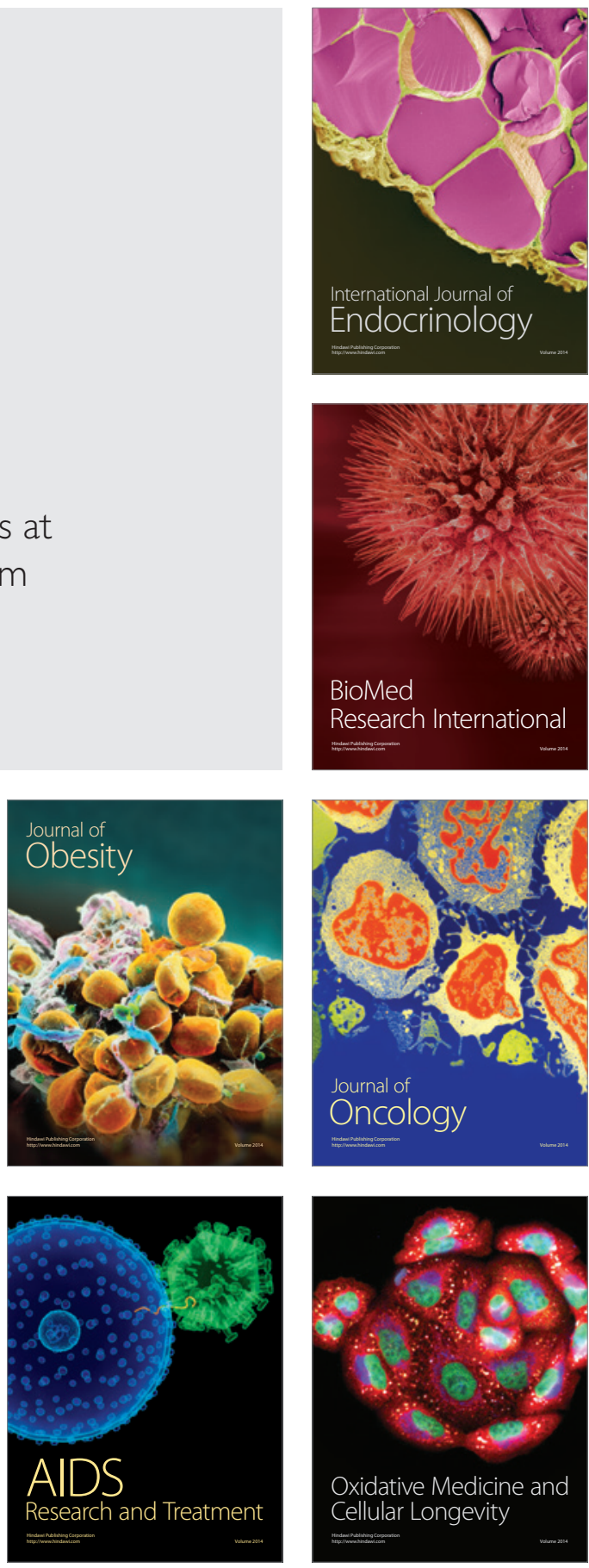